Journal of Educational

Technology \& Online Learning

Volume 4 | Issue $3 \mid 2021$

http://dergipark.org.tr/jetol

\title{
Development of the learning management systems evaluation scale based on transactional distance theory
}

\author{
Esra Barut Tuğtekin ${ }^{\text {* }}$ (D) \\ a Inonu University, Distance Education Application and Research Center, Malatya, Turkey.
}

Suggested citation: Barut Tuğtekin, E. (2021). Development of the learning management systems evaluation scale based on transactional distance theory. Journal of Educational Technology \& Online Learning, 4(3), 503-515.

\begin{tabular}{|c|c|}
\hline Article Info & Abstract \\
\hline $\begin{array}{l}\text { Keywords: } \\
\text { Learning Management } \\
\text { Systems } \\
\text { Transactional Distance Theory } \\
\text { Scale development } \\
\text { Structural reliability } \\
\text { HTMT }\end{array}$ & $\begin{array}{l}\text { This study aimed to develop the Learning Management Systems Evaluation Scale } \\
\text { (LMSES) with reference to Transactional Distance Theory (TDT). At the first stage of } \\
\text { the scale development, it was observed that } 19 \text { items with three factors explained } 63.73 \% \\
\text { of the total variance. The variance amounts explained by the scale factors are Dialogue } \\
(\mathrm{D}=8 \text { items, } 23.06 \%) \text {, Structure }(\mathrm{S}=7 \text { items, } 25.74 \%) \text {, and Autonomy ( } \mathrm{A}=4 \text { items, } \\
14.93 \%) \text {. As a result of the confirmatory factor analysis performed at the second stage of } \\
\text { the scale development, it was determined that the scale had a sufficient reliability } \\
\text { coefficient }(\mathrm{Cronbach} \mathrm{s} \text { alpha } \mathrm{S}=0.90, \mathrm{D}=0.89, \mathrm{~A}=0.82) \text { and fit indices }\left(\chi^{2}=252.78 \text {; }\right. \\
\text { sd=146; } \chi^{2} / \mathrm{sd}=1.73 \text {; CFI }=0.95 \text {, NFI }=0.90, \mathrm{GFI}=0.89 \text {, AGFI }=0.85 \text {, SRMR=0.06, } \\
\mathrm{RMSEA}=0.06 ; \mathrm{p}<0.001) \text {. The overall Cronbach's alpha coefficient of the scale was } \\
\text { calculated as } 0.94 \text {. Furthermore, the structural reliability of the scale }\left(\mathrm{S}_{\omega}=0.90 \text {, }\right. \\
\left.\mathrm{S}_{\mathrm{AVE}}=0.57 ; \mathrm{D}_{\omega}=0.88, \mathrm{D}_{\mathrm{AVE}}=0.49 ; \mathrm{A}_{\omega}=0.82, \mathrm{~A}_{\mathrm{AVE}}=0.54\right) \text { and the results of the HTMT ( } \mathrm{S} \text { - } \\
\left.\mathrm{D}=0.68, \mathrm{r}_{\mathrm{A}-\mathrm{D}}=0.80, \mathrm{r}_{\mathrm{A}-\mathrm{S}}=0.76\right) \text { correlation ratio analysis were examined, and the evidence } \\
\text { for the validity of the scale was supported. According to these research findings, the } \\
\text { LMSES has the potential to provide a statistically verified measurement structure based } \\
\text { on TDT and support advanced theoretical and statistical studies. }\end{array}$ \\
\hline
\end{tabular}

\section{Introduction}

The rapid development of communication technologies and the proliferation of information have played a role in the spread of education and training systems worldwide. Especially in the last decade, online learning has become an important part of higher education, while the COVID-19 pandemic has made e-learning a necessity. In periods such as the pandemic when restrictions are increased, information technologies offer alternative solutions in all areas. In this age when we can see that information technologies can be adapted to all areas of life, it is inevitable to discuss the use of information technologies in the domain of education, especially considering the level of participation. Technology has always been a helpful tool in performing simple tasks such as improving the traditional learning process (Raza et al., 2021). E-learning tools have made it possible to continue the learning process in periods such as the pandemic when restrictions are intense and face-to-face education is interrupted (Zwain, 2019). In the digital age, when technology has become indispensable for life, learning tools and learning environments have also turned to digitalization in accordance with e-learning. Multimedia tools, from text-based information sources to audios and videos, from simple web pages to interactive learning sources, have experienced a significant uptrend in recent years. The virtualization of learning sources in the digitalizing world has created a group of online learners and brought the learner to the position of information receiver and producer. The fact that e-learning tools can be developed and adapted to educational environments has paved the way for learners to be active learners rather than passive listeners. E-learning tools are frequently used in today's technology age since 
students can structure information as active users and use many interactive tools together. The rapid development of information technologies has supported online learning or e-learning applications. With elearning, students can acquire new information and access educational material at any time, share their knowledge and use assessment systems that can measure their comprehension. With e-learning, students can use technical tools and experience learning independently. Teachers, on the other hand, can monitor students through homework, discussion forums, and other activity tools and find the opportunity to meet and evaluate students on digital platforms (Muhardi et al., 2020). The digital learning environment where e-learning is carried out in a planned and holistic way is Learning Management Systems (LMS). LMS, which is designed to make it easier for students to structure information themselves, integrate multiple learning sources and flexibly present them, draws attention as an important learning tool (Chen \& Cui, 2020).

\section{Literature}

\subsection{Learning Management Systems (LMS)}

LMS are internet-based software applications used to access, plan, implement, perform, monitor, and evaluate learning content by communicating with teachers and students (Elfeky, 2020). Common examples of LMS include a lot of different software such as Moodle, Canvas, Blackboard, and ALMS. In LMS, in addition to loading learning materials with word processing programs, more interactive structures can be used by establishing various discussion and chat environments, and achievement can be evaluated with measurement tools. At the same time, various features such as keeping an e-portfolio, saving notes, schedule and calendar reminders can be provided via LMS, and multimedia materials such as music, sound, and animation can be used (Byrd, 2018). Animated videos can be prepared with multimedia content, and virtual classrooms can be created, enabling students to interact with a virtual laboratory (Hamzah et al., 2019). In addition to accessing the content provided by their teachers, students can also use LMS to communicate with their peers. LMS have become a widely used learning tool to create, distribute, and monitor various learning and teaching materials, supported by innovative technology, especially in higher education, providing a gateway to learning and teaching (Mershad \& Wakim, 2018; Sinclair \& Aho, 2018). Therefore, it is important to use LMS effectively and efficiently in education processes. Thus, LMS should be preferred in line with the educational purpose. Accordingly, it should be discussed which criteria should be taken into account in the use and preference of LMS. Considering that LMS is used as a distance education method in e-learning processes, it is necessary to examine LMS based on distance education theory for effective use. Similarly to the structure of distance education and LMS, it is thought that transactional distance theory, in which learning is evaluated within the concept of distance, will create an appropriate theoretical framework in explaining LMS in this study.

\subsection{Transactional Distance Theory and Theoretical Framework}

The main feature of distance education is that the teacher and the student do not have to be physically in the same place (Cohen et al., 2007). While this situation emphasizes that there is a real physical distance between the teacher and the student, the e-learning environment allows communication in the internet environment despite this distance. Taking the distance in distance education, which is the basis of elearning, as a theoretical basis, Moore used it in a broader sense and evaluated it as not only a physical distance but also a social distance (Moore, 1989). In the literature, this distance was interpreted as the distance caused by the psychological and communicative gap allowing for misunderstanding (Moore \& Kearsley, 1996). Based on this, Moore (1993) developed Transactional Distance Theory (TDT). The concept of the transaction is explained as "behavioural patterns that occur in any situation, environment and individuals affecting each other" (Moore \& Kearsley, 1996). When distance is considered within the framework of this concept, the distance that prevents individuals from affecting each other is interpreted as transactional distance (Horzum, 2013). TDT consists of two dimensions, including distance and student autonomy (Moore, 1996). The distance dimension is divided into the structure and dialogue components 
(McIsaac \& Gunawardena, 1996). The dialogue component in the distance dimension in distance education explains the two-way interaction between student-teacher and student-student. The program with high dialogue allows for unpredictable new learning outcomes and new findings. The structure component refers to the combination of elements that can meet the needs of students in course activities and contents at the time of student-content and student-interface interaction. The over-structured program results in an inflexible learning environment that limits the student's ability to perform personal learning in different ways. The student autonomy dimension is that students make decisions about the process of self-learning and structure their knowledge within the framework of their own experience (Horzum, 2013). When the implementation of distance education in the e-learning environment is considered within the framework of TDT, preparing an e-learning environment in a way that will increase dialogue and student autonomy may have a positive effect on learning. On the other hand, the structural dimension of the e-learning environment should be reduced, and it should be created flexibly so that the student can use different options. In this context, it is important to take into account the components of TDT while preparing LMS used as today's e-learning environment and to develop them on this basis.

\subsection{Aim of the Study}

It is known that e-learning-based LMS are used extensively in the implementation of distance education, especially in higher education. It is important to prepare LMS in a way enabling meaningful learning that supports students' learning, communication, and motivation. Therefore, it is considered useful to examine LMS based on TDT that structures learning in distance education for effective use. According to this, when the literature was reviewed, it was determined that there was no valid and reliable data collection tool for evaluating the effective use of LMS. Concerning to aforementioned requirement, it was aimed to develop the Learning Management Systems Evaluation Scale (LMSES) based on TDT in this study. In line with this purpose, statistical analyses consisting of dissection, verification, reliability, and validity processes were carried out to develop a valid and reliable LMSES that can serve different e-learning environments.

\section{Methodology}

\subsection{Research Design}

This study was designed based on the scale development process. The study was conducted with the participation of 389 university students, 172 participating in the first stage of the scale development through ALMS, which was used as LMS, and 217 participating in the second stage. In the fall semester of the 20202021 academic year, undergraduate students, who continue their learning with distance education at a state university because of the COVID-19 pandemic restrictions, have voluntarily participated the data collection process for the current research. The provision of the questionnaire to the participants was carried out using Google Forms through the university-wide LMS (i.e., ALMS).

\subsection{Development of the Data Collection Tool}

In the study, a scale development study was carried out to evaluate the LMS used in universities. Before creating the scale items, it was revealed that there were data collection tools related to the evaluation of internet-based learning environments in the literature, but there was no validated and verified scale concerning the evaluation of LMS. In line with this, the data collection tools created regarding the evaluation of LMS, internet-based systems and courses at the beginning of the scale development process were examined (Arbaugh et al., 2008; Ateş, 2013; Demirkol \& Şeneler, 2018; Horzum, 2011; Gürses, 2006; Kılıç Çakmak et al., 2011; Mtebe, \& Raisamo, 2014; Özonur et al., 2019; Sarıkaya, 2014; Turan \& Canal, 2011; Zaharias, \& Pappas, 2016). In this context, firstly, an item pool of 36 questions was created regarding relevant literature. The created items were evaluated within the framework of TDT and constructed in a way to support the dimensions of the theory. The number of constructed items was reduced to 24 and turned into a multiple-choice questionnaire. One of the items is a reverse item that contains a negative statement and should be reverse scored. To receive expert opinion for the 24 -item questionnaire, one-to-one 
interviews were held with five academicians, including experts in the domains of Information Technologies, Assessment and Evaluation and Education Programs and Teaching, and the items were discussed. The comprehensibility, scope, clarity, and way of expression of the questionnaire items were examined with the expert opinions received, and they were reconstructed in the Likert format. Thus, a form of 24 items in the five-point Likert type progressing from "Strongly disagree" to "Strongly agree" was created.

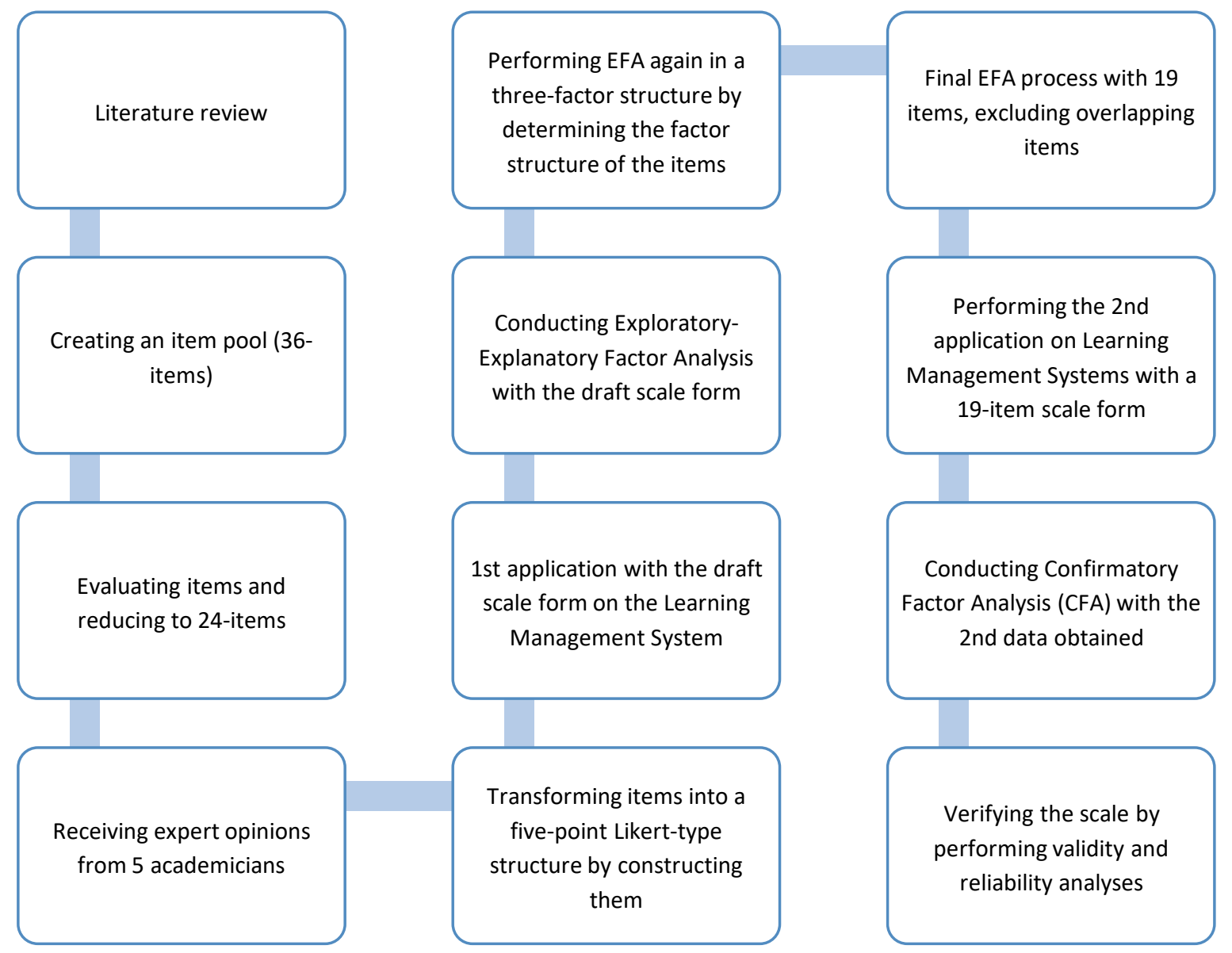

Fig. 1. Scale development process

The 24-item data collection tool, which was created at the first stage to evaluate the LMS of university students within the framework of TDT, was applied to 172 undergraduate students who were receiving education through ALMS and participated voluntarily ( $n$ female $=106, n$ male $=66$ ). The mean age of the participants was $21.92(\mathrm{SD}=4.24 ; \mathrm{n}=172)$. Of these participants, 50.58\% were students of the Faculty of Arts and Sciences, 28.49\% were students of the Faculty of Communication, $6.40 \%$ were students of the Faculty of Education, $5.81 \%$ were students of the Faculty of Health Sciences, $4.65 \%$ were students of the Faculty of Nursing, and $4.07 \%$ were students of the Faculty of Fine Arts and Design. Before analyzing the obtained data, the prerequisites were examined. Analyses were started by reverse scoring an item containing a negative statement. The values of skewness and kurtosis in univariate normality were evaluated by taking the $-1.5,+1.5$ interval as a criterion. Mahalanobis distances were examined for multivariate extreme values (Hodge \& Austin, 2004). To this end, a new variable was created by calculating the mean scores of the scale items. By following a strict attitude over this mean score variable, the data of three persons above the critical value of 3.84 at alpha 0.05 significance level according to the degree of freedom $(\mathrm{df}=1)$ were sampled. The SPSS 22 packaged software was used in the exploratory-explanatory factor analysis (EFA) 
process of the study, and the AMOS 22 program was used in the confirmatory factor analysis (CFA) process.

The significance of the result $\left(\chi^{2}=2772.83 ; \mathrm{df}=276 ; \mathrm{p}<0.001\right)$ showed that the assumption of multivariate normality and linearity of the data was obtained when Bartlett's test of sphericity was performed to test the conformity of the data obtained from the first questionnaire application with EFA. To determine whether the sample was sufficient for EFA or not, the Kaiser-Meyer-Olkin coefficient was calculated as 0.94, and it was found to be sufficient (Comrey \& Lee, 1992; Çokluk et al., 2012; Pallant, 2007). In the EFA process, the principal components analysis method was used as the factorization method to determine the minimum number of factors that best reflected the relationship between variables, and the Varimax rotation method, which is the most used orthogonal approach (Akbulut, 2010; Aldrich, 1997; Field, 2005), was used as the rotation technique. In determining the number of factors, Kaiser's criterion of eigenvalue greater than 1 and Cattell's scree plot methods were taken into account (Pallant, 2007; Tabachnick \& Fidell, 2007). When the analysis results were examined, it was observed that three factors with eigenvalues greater than 1 were formed for 24 items. At the same time, it was decided that a three-factor structure was suitable due to the horizontalization of points after the third interval in the scree plot (Figure 2).

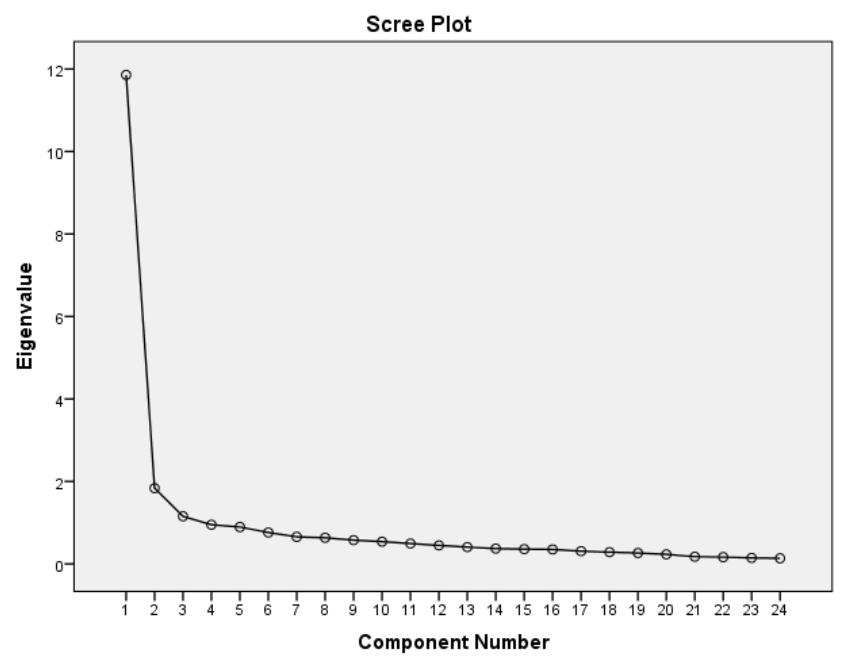

Fig. 2. Scree plot for the first EFA

In the repeated analysis for three factors, it was observed that 24 items explained $62.43 \%$ of the total variance. When the factor loads of the items were examined, it was revealed that the factor loads of the five items were smaller than 0.10, which is the overlapping item limit (Walker \& Madden, 2008). The exclusion of each of the overlapping items from the data set and their effects on variance were examined. It was determined that excluding these items had a low effect on variance and would not adversely affect the content validity of the scale. Therefore, it was decided to exclude the five complex items from the data set. It was observed that the 19 items and the three-factor structure, which were repeated after the aforementioned overlapping items were excluded from the scale, explained $63.73 \%$ of the total variance. Since the first factor alone explains $49.05 \%$ of the scale, firstly, it comes to mind that the scale can be transformed into a single-factor structure. However, the eigenvalues of the three factors were also greater than 1 , and when the meanings of the items under each factor were evaluated, it was found that the items were distributed to the factors following the TDT dimensions. Thus, it was decided to create the scale in a three-factor structure, and the factors were named Dialogue-Communicationality ( $D=8$ items), StructureFormality ( $\mathrm{S}=7$ items), and Autonomy-Functionality $(\mathrm{A}=4$ items). The proportions of the variance amounts explained by the factors rotated by the Varimax technique on their own were determined as $\mathrm{S}=25.74 \%$, $\mathrm{D}=23.06 \%$, and $\mathrm{A}=14.93 \%$, respectively. When Table 1 was examined, it was determined that the eigenvalues of these factors were greater than 1, and the factor loads of the items belonging to the factors varied between 0.57 and 0.82 , and they were greater than the recommended value of 0.30 (Pallant, 2007). 


\section{Table 1.}

Item loads of the factors according to the exploratory factor analysis

\begin{tabular}{|c|c|c|c|}
\hline Factor/Item ${ }^{*}$ & $\begin{array}{l}\text { Factor } \\
\text { Load }\end{array}$ & Eigenvalue & $\begin{array}{l}\text { Variance } \\
\text { Explained }\end{array}$ \\
\hline Structure Factor & & 4.89 & $25.74 \%$ \\
\hline SF1. Required features are easily accessible. & 0.62 & & \\
\hline SF2. All components of the system are coherent and consistent. & 0.58 & & \\
\hline SF3. It has a simple navigation structure. & 0.82 & & \\
\hline SF4. It has a useful design. & 0.80 & & \\
\hline SF5. It is simple to guess what the symbols and menu items used imply. & 0.71 & & \\
\hline SF6. The user interface provides clear instructions for navigating to the content. & 0.77 & & \\
\hline SF7. It is challenging to use. ${ }^{* *}$ & 0.57 & & \\
\hline Dialogue Factor & & 4.38 & $23.06 \%$ \\
\hline DF1. It is easy to interact with other users. & 0.78 & & \\
\hline DF2. The system offers relevant and timely feedback while utilizing. & 0.62 & & \\
\hline DF3. It contains motivational interactive features. & 0.76 & & \\
\hline $\begin{array}{l}\text { DF4. It provides various facilities (i.e., e-mail, forums, etc.) for } \\
\text { asynchronous/synchronous communication. }\end{array}$ & 0.64 & & \\
\hline DF5. It provides a range of supporting systems tools (i.e., e-mail, chat, form, etc.). & 0.65 & & \\
\hline $\begin{array}{l}\text { DF6. It may be integrated into various surroundings (i.e., Blogs, YouTube, Twitter, } \\
\text { LinkedIn contents). }\end{array}$ & 0.68 & & \\
\hline DF7. It has customization options. & 0.73 & & \\
\hline $\begin{array}{l}\text { DF8. It contains attention-grabbing gamification components (i.e., points, badges, } \\
\text { scoreboards, levels, etc.). }\end{array}$ & 0.58 & & \\
\hline Autonomy Factor & & 2.84 & $14.93 \%$ \\
\hline AF1. It is easy to utilize the file upload/download functions. & 0.69 & & \\
\hline AF2. It has reporting features (e.g., for courses, forums, and exams). & 0.73 & & \\
\hline $\begin{array}{l}\text { AF3. It provides information on learning analytics (i.e., the course analyzes, } \\
\text { progress reports, completion rate, etc.). }\end{array}$ & 0.64 & & \\
\hline $\begin{array}{l}\text { AF4. It provides various facilities for measurement and evaluation (i.e., exams, } \\
\text { short exams, homework, peer assessment, group assessment, etc.). }\end{array}$ & 0.60 & & \\
\hline
\end{tabular}

Note. *The scale was implemented and developed in the Turkish language. The Turkish version of the LMSES and related supplementary materials are available upon request to the corresponding author.

***Reverse-worded item.

At the second stage of scale development, to evaluate the verification of the 19-item data collection tool with three factors, which had been previously created, a data collection tool was applied to 217 university students who were receiving education through LMS and voluntarily participated in the study ( $\mathrm{n}_{\text {female }}=115$, $\left.\mathrm{n}_{\text {male }}=102\right)$. The mean age of the participants was $22.06(\mathrm{SD}=4.19 ; n=217)$. Of these participants, $30 \%$ were students of the Faculty of Engineering, $22.1 \%$ were students of the Faculty of Education, $14.3 \%$ were students of the Faculty of Economics and Administrative Sciences, $8.8 \%$ were students of the Faculty of Arts and Sciences, and the remaining $24.9 \%$ were students from other faculties. Before analyzing the obtained data, the prerequisites were examined. Analyses were started by reverse scoring an item containing a negative statement. The values of skewness and kurtosis in univariate normality are in the $-1.5,+1.5$ interval. Mahalanobis distances were examined for multivariate extreme values (Hodge \& Austin, 2004). By following a strict attitude, the data obtained from seven persons that were above the critical value of 3.84 at alpha 0.05 significance level according to the degree of freedom $(\mathrm{df}=1)$ were excluded from the sample because they were extreme. As a result of the preliminary analysis of the items, the three-factor 19item measurement model obtained from the previous EFA was tested using the maximum likelihood method within the scope of CFA. It was observed that the chi-square goodness of fit value obtained as a result of CFA was significant $\left(\chi^{2}=252.78 ; d f=146 ; \mathrm{p}<0.001\right)$. According to Schermelleh et al. (2003), a ratio 
of $\chi^{2} / \mathrm{df}$ below 2 in scale studies developed for large samples indicates a good level of fit $(252.78 / 146=1.73)$. Furthermore, the fit indices of the model in the final CFA result were determined as SRMR $=0.06, \mathrm{CFI}=0.95$, $\mathrm{NFI}=0.90, \mathrm{GFI}=0.89$, AGFI=0.85, and RMSEA=0.06. The approach of the CFI, NFI, GFI, and AGFI fit indices toward 0 indicates a model's misfit, and 1 indicates a perfect fit. In the literature, 0.95 and above in CFI indicates a perfect fit (Hu \& Bentler, 1999; Thompson, 2004), 0.90 and above in NFI indicates a good fit (Tabachnick \& Fidell, 2001; Thompson, 2004). GFI of 0.80 and above (Hair et al., 2010) and AGFI of 0.70 and above (Byrne, 1998; Qi et al., 2004) indicate an acceptable fit. In cases when SRMR is lower than 0.08, it is stated that the model has a good fit (Brown, 2006; Hu \& Bentler, 1999). The approach of the RMSEA value toward 0 indicates a perfect fit, while RMSEA greater than 1 indicates a misfit (Yilmaz, 2004). It is stated that the RMSEA value of the model between 0.08 and 0.1 is acceptable and indicates a moderate fit (Browne \& Cudeck, 1993; Bryne, 2000). As a result, when the CFA result fit index data of the model were examined, it was determined that there were acceptable, good and perfect fit values between the model and the observed data.

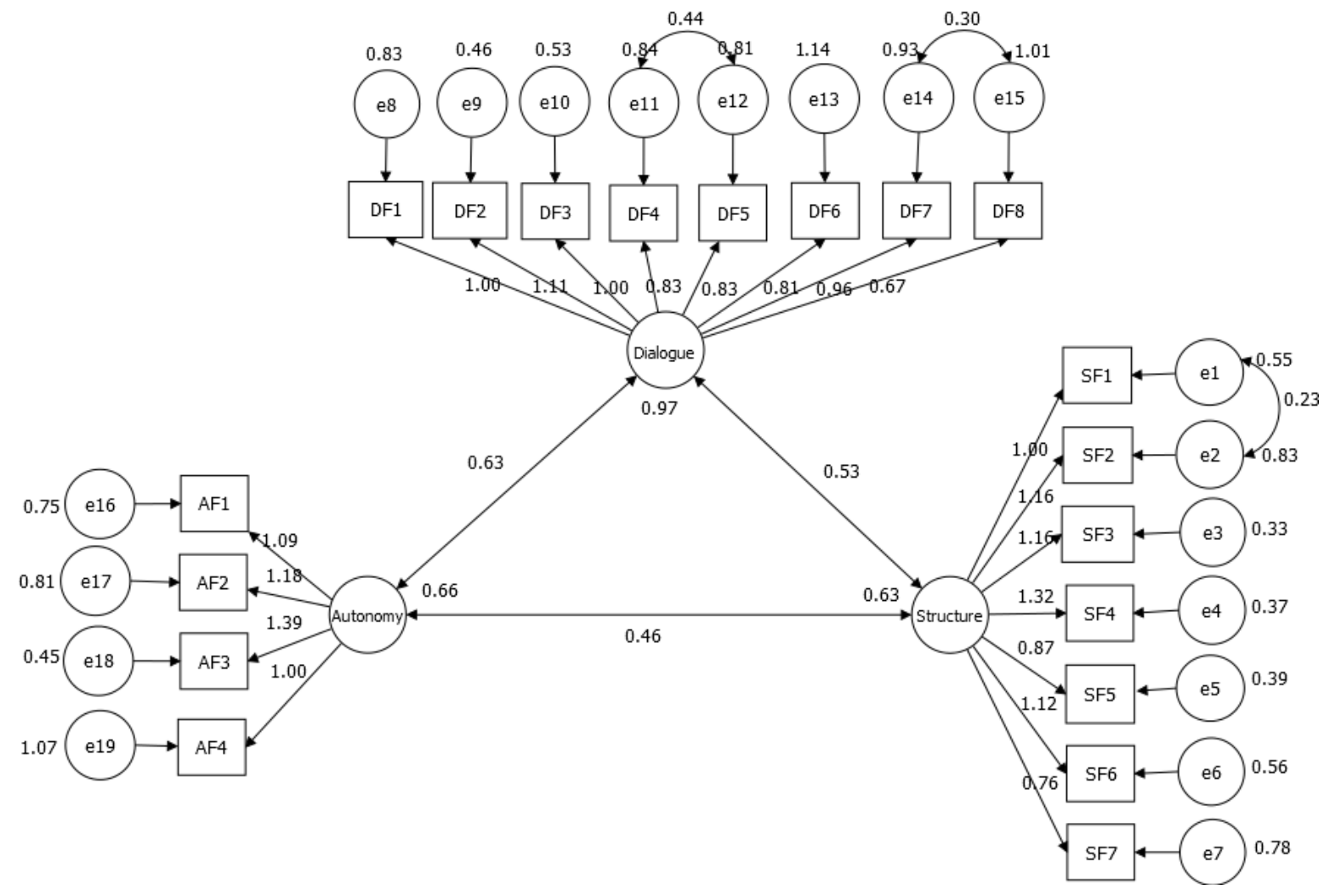

Fig. 3. CFA graph of the measurement model

The path coefficients of the measurement model obtained as a result of CFA and the variance amounts explained by the factors on their items are shown in Figure 1. When the CFA indicators were reviewed, it was determined that there were three modification suggestions. Even if no modification is carried out in the measurement model, the structural values of the scale are sufficient for verification. However, it was determined that the modifications suggested in the analysis outcomes would provide valuable contributions to the chi-square and other fit indices. Therefore, it was decided to carry out the suggested modifications. As a result, according to the CFA result of the scale, the standardized path coefficients of the factors ranged from 0.67 to 1.39 and were found to be statistically significant $(\mathrm{p}<0.001)$.

\subsection{Reliability Results}

Internal consistency coefficients and item-total correlations were calculated based on CFA data to calculate the reliability of the three-factor scale consisting of 19 items. Table 2 shows the reliability analysis and descriptive statistics for all factors of the model. 
When the reliability analysis outcomes of the scale factors were examined, it was determined that they had a Cronbach's Alpha coefficient of 0.9 for the Structure factor, 0.89 for Dialogue and 0.82 for Autonomy (shown in Table 2). The overall Cronbach's Alpha internal consistency coefficient of the scale was 0.94. In the scale development literature in social sciences, the reliability coefficient of the scale between 0.65 and 0.80 is sufficient for its reliability (Vaske, 2008).

Table 2.

Reliability analysis results and descriptive statistics of the scale factors

\begin{tabular}{lcccccccc}
\hline \multirow{2}{*}{ Factor } & $\begin{array}{c}\text { Cronbach's } \\
\text { Alfa }\end{array}$ & $\begin{array}{c}\text { Min- } \\
\text { Max }\end{array}$ & $\boldsymbol{\omega}$ & AVE & Mean & SD & \multicolumn{2}{c}{ Correlation Coefficient } \\
\hline Structure & 0.90 & $7-35$ & 0.90 & 0.57 & 27.11 & 6.22 & $0.62 *$ & Dialogue \\
Dialogue & 0.89 & $8-40$ & 0.88 & 0.49 & 22.15 & 7.68 & 1 & $0.66^{*}$ \\
Autonomy & 0.82 & $4-20$ & 0.82 & 0.54 & 13.91 & 1.17 & $0.69 *$ \\
\hline
\end{tabular}

On the other hand, corrected item-total correlations were found to range from 0.51 to 0.81 for Structure, 0.54 to 0.75 for Dialogue, and 0.55 to 0.75 for Autonomy. In the literature, it is stated that items greater than 0.30 for the item-total correlation value are intended to measure the same statement and distinguish the participants well (Pallant, 2007). Accordingly, it is understood that the items in each factor of the scale measure the same structure together. The high score obtained from the scale shows to what extent the examined LMS is an adequate and useful tool for the participant group based on TDT, to what extent it is suitable for the TDT dimensions and its usability in distance education in the context of the course applied with the participant group. The correlation coefficients between the factors indicate a moderately positive correlation between 0.30 and 0.70 (Büyüköztürk, 2012). Accordingly, when Table 2 is reviewed, it can be stated that the factors of Structure, Dialogue, and Autonomy are in a moderately positive and significant correlation with each other. Therefore, all factors of the scale serve the whole of the scale within the same general purpose.

To test the construct validity of the scale, analysis with convergent and divergent validity is recommended (Fornell \& Larcker, 1981). In the literature, the average explained variance (AVE) value is expected to be smaller than the convergent validity value $(\omega)$, the AVE value to be greater than 0.5 , and the $\omega$ value to be greater than 0.7 (Fornell \& Larcker, 1981; Hair et al., 2010). Moreover, the AVE value greater than 0.4 is also stated as acceptable in the literature (Khaleghinejad \& Ziaaldini, 2015). Furthermore, it is stated in the literature that if the convergent validity value is greater than 0.7 , AVE can be accepted up to 0.4 and is still suitable for construct validity (Fornell \& Larcker, 1981; Huang et al., 2013). Accordingly, in the calculations made for the three-factor scale, it was determined that each of the AVE values is smaller than the structural reliability values $(\omega)$. Structural reliability $(\omega)$ values are greater than 0.7 , and the values greater than 0.4, although only the Dialogue factor is smaller than 0.5 among the AVE values, indicates a relatively acceptable value. This situation emphasizes that the AVE value is affected by the sample size, and it is stated that the AVE value increases from 0.5 to 1 as the sample size increases (dos Santos \& Cirillo, 2021). The sample size for CFA is 210 after excluding the extreme values, and the KMO Bartlett's test of sphericity result, which shows the adequacy of the sample size, is $0.93(\mathrm{p}<0.001)$. According to the KMO Bartlett's test of sphericity result, even if the sample size is sufficient to perform CFA, it is thought that this affects the AVE value to remain at the limit value. It is estimated that the AVE value will show better results if it is done with higher sample size, but it is understood that the available data are in the acceptable range.

Stating that the variance-based comparisons of Fornell and Larcker (1981) regarding structural reliability would not be sufficient in determining the discriminant validity, Henseler et al. (2015) proposed a new analysis technique for validity. The Heterotrait-Monotrait Ratio of Correlations (HTMT) criterion was taken into account in the examination of discriminant validity according to this technique. According to the HTMT criterion, the correlation threshold value should be lower than 0.85 when evaluated strictly (Clark 
\& Watson, 1995; Kline, 2011) and lower than 0.90 when evaluated flexibly (Gold et al., 2001; Teo et al., 2008) (Henseler et al., 2015). The HTMT analysis results suggested as a new approach for the discriminant validity of the scale are presented in Table 3.

Table 3.

Heterotrait-Monotrait (HTMT) Correlation Ratio Analysis Results

\begin{tabular}{lcc|c}
\hline & Dialogue & Structure & Autonomy \\
\hline Structure & 0.68 & & \\
Autonomy & 0.80 & 0.76 & \\
\hline
\end{tabular}

When the HTMT analysis results given in Table 3 were investigated, it was determined that the HTMT results calculated among the factors of the developed scale were lower than the suggested critical values. Accordingly, it was concluded that the scale had suitable values for HTMT analysis and had discriminant validity. The fact that the HTMT analysis results, which is an alternative method for validity analysis, are also suitable and the AVE value is within acceptable ranges does not pose an obstacle to the average explained variance and the scale's validity. Therefore, it is understood that the scale meets various criteria for validity with all its factors in addition to the reliability criteria.

\section{Discussion and Conclusion}

In the study, the LMSES, including three factors consistent with the TDT framework, was developed. Although the scale has three different factors of Structure, Dialogue, and Autonomy, it is measured in a five-point Likert type in a consistent and correlated manner with each other. In addition, the fact that the variance of the single-factor structure was quite high during the dissection process of the scale revealed the idea that the scale could be evaluated as a single-factor scale. Along with the development of a three-factor scale model, the second-order measurement model was also tested to measure the single-factor structure of the scale based on TDT. This is the step examined after determining the sub-factors in the scale development process (Koc \& Barut, 2016). It is recommended to evaluate the use of the total of the scale under a single structure (Noar, 2003). When the second-order single-factor measurement model of the scale was tested, it was observed that the model was suitable in terms of fit indices and good levels. When the three-factor structure of the scale and the single-factor structure were compared, it was determined that the three-factor structure had better fit indices, but both models were suitable for use. Thus, an alternative model to the first-order three-factor measurement model of the scale was presented. Evidence for the singlefactor use of the scale was provided by establishing the second-order measurement model. The decision regarding the factor structure of the scale was left to the preference of the researchers in the context of the theoretical basis. Researchers can perform analyses with the three-factor structure or use it as a variable within the framework of a single structure over the total or mean scores of all items.

Theoretically, the LMSES offers a statistically verified measurement structure within the framework of TDT. Thus, it is understood that TDT is a valid and reliable measurement tool in evaluating LMS used in distance education. In addition, to determine the effect of LMS used in determining the effectiveness of the education provided, the LMSES developed in this study can contribute as a useful data collection tool. It also emphasizes the lack of a valid and reliable data collection tool for evaluating LMS and the contribution and importance of the LMSES, which was developed to fill this gap. At the same time, it is thought that the LMS developed regarding TDT and the verification of the three-factor and one-factor measurement model will support its use with different variables for researchers. With the use of the LMSES, improvements can be made by determining the use of the correct LMS in the context of variables such as the participant group or the intended purpose. Considering the effect of effective use of LMS on the learning process (Zwain, 2019), the necessity of evaluating LMS and the use of LMS developed for this purpose arises. It is estimated 
that LMS, a mandatory solution to eliminate disruptions in distance education during the pandemic, will continue to be used for a long time in the future. Moreover, educators who get used to providing their courses through distance education during the current period experienced the convenience of distance education compared to face-to-face education. Therefore, even if the pandemic conditions come to an end, it is thought that LMS will be used in the long term, and the development of a scale for evaluating LMS has the potential to contribute to educators and researchers. Thus, multi-dimensional evaluation processes can be employed to design e-learning environments that will improve the learning process.

\section{Suggestions and Limitations}

In conclusion, it is thought that this study and the LMSES with proven validity and reliability will contribute to the literature. The findings present an important rationale in encouraging the LMSES to theoretical and statistical studies based on TDT. This study has the potential to contribute to the research of LMS, used by necessity in higher education, especially during the COVID-19 pandemic, in the context of various variables. The relationship of the LMS used with the student's interest, attitude, and motivation can be a suggested subject for future studies. However, the necessity to explain the limitations of the study should not be overlooked. The current study was conducted during the compulsory distance education procedure, which was put into use urgently during the COVID-19 pandemic era. Therefore, the implementation of the research was carried out with learners who were thought to be affected physically, socially and psychologically due to the LMS and COVID-19 pandemic restrictions used in the emergency distance education procedure amid the pandemic. There is hence the possibility that the research procedure will be affected by pandemic restrictions that researchers cannot manipulate. In addition to this, the LMSES developed in this study is limited within the framework of TDT and the LMS where the research application is carried out (i.e., ALMS). In addition, since it is limited in the context of validity and reliability tests applied during the scale development process, it can be tested with different analysis techniques in future studies. On the other hand, due to the limited number of participants in the study, the LMSES can be tested and verified in different participant groups. Furthermore, due to the intensive use of LMS in higher education, the scale was developed with a limitation to the sample of university students. However, considering that during the COVID-19 pandemic, distance education is provided at each of the education levels, the LMSES can be re-developed by adapting the scale in the context of samples at various educational levels (i.e., K-12 level, etc.).

\section{References}

Akbulut, Y. (2010). Using SPSS in social sciences: Frequently used statistical analyses and solved problems. İdeal Kültür Yayıncılık.

Aldrich, J. (1997). R. A. Fisher and the making of maximum likelihood 1912-1922. Statistical Science, 12(3), 162-176. https://doi.org/10.1214/ss/1030037906

Arbaugh, J. B., Cleveland-Innes, M., Diaz, S. R., Garrison, D. R., Ice, P., Richardson, J. C., \& Swan, K. P. (2008). Developing a community of inquiry instrument: Testing a measure of the community of inquiry framework using a multi-institutional sample. The Internet and Higher Education, 11(3-4), 133-136.

Ateş, A. (2013). A scale proposal for evaluation of the educational web sites. Eğitim Teknolojileri Araştırmaları Dergisi, 4(1). http://www.et-ad.net/

Brown, T. A. (2006). Confirmatory factor analysis for applied research. New York, The Guilford Press.

Browne, M. W., \& Cudeck, R. (1993). Alternative ways of assess-ing model fit. In: K. Bollen \& J. S. Long, eds. Testing structural equation models, 136-162. Newbury Park, CA: Sage. 
Bryne, B. M. (2000). Structural equation modeling with Amos: Basic concepts, applications, and programming. Mahwah, NJ:Erlbaum.

Büyüköztürk, Ş. (2012). Sosyal bilimler için veri analizi el kitabı (16. Baskı). Ankara: Pegem Akademi Yayınc1lik.

Byrd, R. (2018). Using appropriate E-learning systems to optimize teaching and learning. GSTF Journal on Computing, 2(3).

Byrne, B. M. (1998). Structural equation modeling with LISREL, PRELIS and SIMPLIS: Basic concepts, applications, and programmings. London, Lawrence Erlbaum Assocatiates, Publishers.

Çakmak, E. K., Güneş, E., Çiftçi, S., \& Üstündağ, M. T. (2011). Developing a web site usability scale: The validity and reliability analysis \& implementation results. Pegem Journal of Education and Instruction, 1(2), 31-40.

Cohen, L., Manion, L., \& Morrison, K. (2007). Research methods in education (6th ed). London and New York: Routledge.

Çokluk, Ö., Şekercioğlu, G., \& Büyüköztürk, Ş. (2012). Sosyal bilimler için çok değişkenli istatistik: SPSS ve LISREL uygulamaları (2nd edition). Ankara: Pegem Akademi.

Comrey, A. L., \& Lee, H. B. (1992). Interpretation and application of factor analytic results. In: A First Course on Factor Analysis (2nd edition). Hillsdale, NJ: Lawrence Erlbaum.

Demirkol, D., \& Şeneler, Ç. (2018). A Turkish translation of the system usability scale: The SUS-TR. Usak University Journal of Social Sciences, 11(3), 237-253. http://dx.doi.org/10.29217/uujss.495

dos Santos, P. M., \& Cirillo, M. Â. (2021). Construction of the average variance extracted index for construct validation in structural equation models with adaptive regressions. Communications in Statistics-Simulation and Computation, 1-13.

Elfeky, A. I. M., Masadeh, T. S. Y., \& Elbyaly, M. Y. H. (2020). Advance organizers in flipped classroom via e-learning management system and the promotion of integrated science process skills. Thinking Skills and Creativity, 35, 100622. https://doi.org/10.1016/j.tsc.2019.100622

Field, A. (2005). Discovering statistics using SPSS (2nd ed.). London, England: Sage.

Fornell, C., \& Larcker, D. F. (1981). Evaluating structural equation models with unobservable variables and measurement error. Journal of Marketing Research, 18(1), 39-50. https://doi.org/10.2307/3151312

Fraenkel, J.R., Wallen, N. E. \& Hyun, H. H. (2011). Validity and reliability, how to design and evaluate research in science education (8th Edition). Mc Graw-Hill Companies, 393-394.

Gürses, E. A. (2006). Usability in library WEB sites and design based on usability guidelines. Hacettepe University Institute of Social Sciences, Doctoral of Thesis.

Hair, J. F., Black, W. C., Babin, B. J., \& Anderson, R. E. (2010). Multivariate data analysis (7th ed.). Englewood Cliffs, Prentice Hall.

Hamzah, M. L., Rukun, K., Rizal, F., \& Purwat1, A. A. (2019). A review of increasing teaching and learning database subjects in computer science. Revista ESPACIOS, 40(26). http://www.revistaespacios.com/a19v40n26/a19v40n26p06.pdf

Henseler, J., Ringle, C. M., \& Sarstedt, M. (2015). A new criterion for assessing discriminant validity in variance-based structural equation modeling. Journal of the academy of marketing science, 43(1), 115-135. https://doi.org/10.1007/s11747-014-0403-8 
Hodge, V.J., \& Austin, J. (2004). A survey of outlier detection methodologies. Artificial Intelligence Review, 22(2), 85-126. https://link.springer.com/article/10.1023/B:AIRE.0000045502.10941.a9

Horzum, M. B. (2010). Uzaktan eğitimde uzaklığın boyutları ve tasarımı: coğrafi uzaklığa karşın transaksiyonel (psikolojik ve iletişimsel) uzaklığın azaltılması [Distance in Distance Education]. The Journal of SAU Education Faculty, 20, 95-118.

Horzum, M. B. (2011). Developing transactional distance scale and examining transactional distance perception of blended learning students in terms of different variables. Educational Sciences: Theory \& Practice, 11(3), 1571-1587.

Hu, L. T., \& Bentler, P. M. (1999). Cutoff criteria for fit indexes in covariance structure analysis: Conventional criteria versus new alternatives. Structural Equation Modeling: A Multidisciplinary Journal, 6(1), 1-55. https://doi.org/10.1080/10705519909540118

Huang, C., Wang, Y., Wu, T., \& Wang, P. (2013). An empirical analysis of the antecedents and performance consequences of using the moodle platform. International Journal of Information and Educational Technology, 3(2), 217-221. https://doi.org/10.7763/IJIET.2013.V3.267

Khaleghinejad, A., \& Ziaaldini, M. (2015). Relationship between employees' safety climate and safety performance with respect to mediating effect of safety knowledge and safety motivation in sarcheshmeh copper complex. Health and Safety at Work, 5(4), 69-86.

Koc, M., \& Barut, E. (2016). Development and validation of New Media Literacy Scale (NMLS) for university students. Computers in Human Behavior, 63, 834-843. https://doi.org/10.1016/j.chb.2016.06.035

McIsaac, M.S., \& Gunawardena, C.N. (1996). Distance education. Ed: D.H. Jonassen, Handbook of Research for Educational Communications and Technology: A Project of The Association for Educational Communications and Technology, 403-437. New York: Simon \& Schuster Macmillan.

Mershad, K., \& Wakim, P. (2018). A learning management system enhanced with internet of things applications. Journal of Education and Learning, 7(3), 23. http://doi.org/10.5539/jel.v7n3p23

Moore, M. G., (1989). Three types of interaction. The American Journal of Distance Education, 3(2), 1-7.

Moore, M.G. (1993). Theory of transactional distance. In D. Keegan (ed.), Theoretical Principles of Distance Education, 22-38. New York: Routledge.

Moore, M.G., \& Kearsley, I.G. (1996). Distance education: A systems view. Wadsworth Publishing Company.

Mtebe, J. S., \& Raisamo, R. (2014). A model for assessing learning management system success in higher education in sub-saharan countries. The Electronic Journal of Information Systems in Developing Countries, 61(1), 1-17.

Muhardi, M., Gunawan, S. I., Irawan, Y., \& Devis, Y. (2020). Design of web based LMS (learning management system) in SMAN 1 kampar kiri hilir. Journal of Applied Engineering and Technological Science (JAETS), 1(2), 70-76. https://doi.org/10.37385/jaets.v1i2.60

Noar, S. M. (2003). The role of structural equation modeling in scale development. Structural Equation Modeling, 10(4), 622-647. https://doi.org/10.1207/S15328007SEM1004_8

Özonur, M., Kamışlı, H., Yelken, T. Y., \& Tokmak, H. S. (2019). Investigation of distance education students' opinions about the ENOCTA learning management system. Mehmet Akif Ersoy University Journal of Education Faculty, (50), 283-302. 
Pallant, J. (2007). SPSS survival manual: A step by step guide to data analysis using SPSS for windows. 3 ed. Sydney: McGraw Hill.

Raza, S. A., Qazi, W., Khan, K. A., \& Salam, J. (2021). Social Isolation and acceptance of the learning management system (LMS) in the time of COVID-19 Pandemic: An expansion of the UTAUT model. Journal of Educational Computing Research, 59(2), 183-208. https://doi.org/10.1177/0735633120960421

Sarıkaya, Y. (2014). Okul deneyimi ve öğretmenlik uygulaması dersleri için geliştirilen web tabanlı bir sistemin kullanışlığının incelenmesi. Fırat University Institute of Education Sciences Master of Thesis.

Schweizer, K., Moosbrugger, H., \& Schermelleh-Engel, K. (2003). Models for hierarchical structures in differential psychology. Methods of Psychological Research Online, 8(2), 159-180. http://www.mpr-online.de

Sinclair, J., \& Aho, A. M. (2018). Experts on super innovators: Understanding staff adoption of learning management systems. Higher Education Research \& Development, 37(1), 158-172. https://doi.org/10.1080/07294360.2017.1342609

Tabachnick, B., \& Fidell, L. S. (2001). Using multivariate statistics (4th ed.). Needham Heights: Allyn \& Bacon.

Thompson, B. (2004). Exploratory and confirmatory factor analysis: Understanding concepts and applications. American Psychological Association.

Turan, O. S., \& Canal, M. R. (2011). Usability study of learning management system; example of the Gazi English Language School. Journal of Information Technologies, 4(3), 47-52.

Walker, J., \& Madden, S. (2008). Factor analysis, path analysis, and structural equation modeling. Statistics in Criminology and Criminal Justice: Analysis and Interpretation (3rd ed.). USA: Jones \& Bartlett Publishers, 325-51.

Yılmaz, V. (2004). LISREL ile yapısal eşitlik modelleri: Tüketici şikayetlerine uygulanması. Anadolu University Journal of Social Sciences, 4(1), 77-90.

Zaharias, P., \& Pappas, C. (2016). Quality management of learning management systems: A user experience perspective. Current Issues in Emerging eLearning, 3(1), 5.

Zwain, A. A. A. (2019). Technological innovativeness and information quality as neoteric predictors of users' acceptance of learning management system: An expansion of UTAUT2. Interactive Technology and Smart Education, 16(3), 239-254. https://doi.org/10.1108/ITSE-09-2018-0065 